\title{
Gene delivery to aortocoronary saphenous vein grafts in a large animal model of intimal hyperplasia
}

\author{
Jason A. Petrofski, MDa \\ Jonathan A. Hata, MD \\ Thomas R. Gehrig, $M D^{b}$ \\ Steven I. Hanish, MDa \\ Matthew L. Williams, MD ${ }^{a}$ \\ Richard B. Thompson, $\mathrm{MD}^{\mathrm{a}}$ \\ Cyrus J. Parsa, MD \\ Walter J. Koch, $\mathrm{PhD}^{\mathrm{a}}$ \\ Carmelo A. Milano, MD
}

From the Departments of Surgery ${ }^{\mathrm{a}}$ and Medicine, ${ }^{\mathrm{b}}$ Duke University Medical Center, Durham, NC.

Read at the Eighty-third Annual Meeting of The American Association for Thoracic Surgery, Boston, Mass, May 4-7, 2003.

This work was supported in part by $\mathrm{Na}$ tional Institutes of Health Grant HL65360 and NRSA 5F32-HL-68437-02.

Received for publication April 10, 2003; revisions requested June 12, 2003; accepted for publication July 22, 2003.

Address for reprints: Carmelo A. Milano, MD, Box 3043, Department of Surgery, Duke University Medical Center, Durham, NC 27703 (E-mail: milan002@mc.duke. edu).

J Thorac Cardiovasc Surg 2004;127:27-33 0022-5223/\$30.00

Copyright (C) 2004 by The American Association for Thoracic Surgery

doi:10.1016/j.jtcvs.2003.07.032
Objective: More than 50\% of aortocoronary saphenous vein grafts are occluded 10 years after surgery. Intimal hyperplasia is an initial, critical step in the progression toward occlusion. To date, no clinically relevant large animal models of aortocoronary saphenous vein graft intimal hyperplasia have been fully characterized. Gene therapy holds promise as a novel treatment for aortocoronary saphenous vein graft intimal hyperplasia. The 2 objectives of this study are to characterize a canine model of aortocoronary saphenous vein graft intimal hyperplasia and to demonstrate that ex vivo gene delivery is possible in these grafts using adenoviral vectors.

Methods: Ten dogs underwent aortocoronary bypass grafting using saphenous veins. Six dogs underwent serial arteriograms to monitor graft patency. On postoperative day 90, the dogs were killed and their grafted and nongrafted saphenous veins were studied histologically. Four dogs underwent the same procedure, but their saphenous veins were treated with $1 \times 10^{12}$ total viral particles of a replicationdeficient, recombinant adenovirus containing $\beta$-galactosidase $(\mathrm{n}=2)$ or the $\beta$-adrenergic receptor kinase carboxyl terminus $(\mathrm{n}=2)$. These animals were killed on postoperative day 7 for determination of transgene expression.

Results: All grafts were demonstrated patent by arteriogram before the animals were killed. The mean intimal area of the saphenous vein grafts was increased when compared with that of the nongrafted saphenous veins $\left(2.83 \mathrm{~mm}^{2}\right.$ vs $0.09 \mathrm{~mm}^{2}, P$ $<.0008$ ). Adenoviral-treated saphenous vein grafts demonstrated positive transgene expression either by $\mathrm{X}$-gal staining ( $\beta$-galactosidase) or Northern analysis $(\beta$ adrenergic receptor kinase carboxyl terminus).

Conclusion: This study characterizes a clinically relevant canine model of aortocoronary saphenous vein graft intimal hyperplasia. In addition, it demonstrates that adenoviral vectors can be delivered ex vivo to the saphenous vein graft vessel wall at subphysiologic distension pressures. This model may be used in future studies to manipulate molecular targets critical in aortocoronary saphenous vein graft intimal hyperplasia.

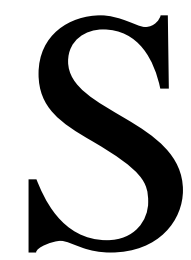

aphenous vein grafts (SVGs) are the most common conduit used for surgical revascularization procedures, including coronary artery bypass grafting. Unfortunately, these grafts are susceptible to the development of intimal hyperplasia (IH) and accelerated atherosclerosis, which result in 5- and 10-year failure rates of $20 \%$ and $50 \%$, respectively. ${ }^{1,2} \mathrm{IH}$ is a chronic structural lesion that develops after vein graft implantation and leads to luminal stenosis and occlusion. It is generally defined as 
abnormal migration and proliferation of vascular smooth muscle cells (VSMCs) with associated deposition of an extracellular connective tissue matrix. SVG IH has been demonstrated in experimental models of vessel injury, inflammation, and increased wall stress. ${ }^{3}$ Accordingly, multiple interventions have been proposed to limit endothelial trauma and inflammation and several are now standard of care (eg, the "no touch" SVG harvest technique and postoperative aspirin therapy). ${ }^{4-6}$ Despite these treatments, longterm SVG failure secondary to IH remains an important cause necessitating redo coronary artery bypass grafting.

More recently, novel molecular approaches to inhibit IH have been proposed and studied. Specifically, multiple molecular targets have been identified as critical regulators of the VSMC proliferation and migration that result in IH and graft stenosis. ${ }^{7-11}$ The possibility of delivering transgenes selectively into the vessel wall to inhibit critical molecular pathways holds considerable promise as a therapeutic tool. The hope is that local production of the transgene product will translate into reduced VSMC proliferation and, ultimately, improved SVG durability.

Gene therapy has been used successfully to inhibit VSMC proliferation and migration in multiple in vitro studies. Gene therapy has also been shown to inhibit IH in several in vivo studies of noncoronary vein grafts. Most often, these studies have used naked DNA plasmids or transgenes delivered in replication-deficient viral vectors. ${ }^{7-11}$ Similar therapies may be useful in preventing aortocoronary SVG $\mathrm{IH}$, but no clinically relevant large animal models of this pathologic process have been quantitatively characterized. Such a model is appealing because it allows an opportunity to study the efficacy of gene therapy in a setting that may provide a bridge to clinical trials.

The 2 objectives of this study are (1) to characterize a canine model of aortocoronary SVG IH and (2) to demonstrate efficient transgene expression in the SVG vessel wall using an ex vivo treatment with adenoviral vectors.

\section{Methods}

\section{SV Harvesting}

Animals used in this study were mongrel dogs (weighing 27-32 $\mathrm{kg}$ ). All procedures were performed in accordance with the regulations adopted by the National Institutes of Health and approved by the Animal Care and Use Committee of Duke University. After placement of an intravenous line, each dog was sedated with sodium pentothal $(10 \mathrm{mg} / \mathrm{kg})$. The dog was intubated, and anesthesia was maintained with inhaled isoflurane (1\%-5\%). The animal was anticoagulated with heparin $(100 \mathrm{U} / \mathrm{kg})$ to an activated clotting time greater than 300 . After sterile preparation, 7 to $10 \mathrm{~cm}$ of SV was harvested from the left hind leg. The SV was flushed and submerged in 3\% albumin until anastomoses were performed. The hind leg was closed in layers.

\section{Treatment of Vein Grafts with Adenoviral-Mediated Transgene}

The adenoviral backbone for the vectors is a second-generation, replication-deficient serotype- 2 adenovirus with deletions of the E1 and E4 genes. ${ }^{12}$ The deletions of these genes render the adenovirus unable to replicate. The coding sequences for cytoplasmic $\beta$-galactosidase $(\beta$-gal) and the $\beta$-adrenergic receptor kinase carboxyl terminus ( $\beta$ ARKct) were spliced into this adenoviral backbone to generate the vectors Adeno- $\beta$-gal and Adeno$\beta$ ARKct. ${ }^{12}$ For animals treated with adenovirus $(n=4)$, the distal tip of the SV was ligated after routine inspection for defects, and $1 \times 10^{12}$ total virus particles were thawed and suspended in $3 \mathrm{~mL}$ of phosphate-buffered saline (PBS). This solution was delivered intraluminally with a measured distension pressure of approximately $10 \mathrm{~mm} \mathrm{Hg}$. After a 20-minute incubation time, the distal $\mathrm{SV}$ tip was reopened. The SV was flushed with heparinized saline and resubmerged in 3\% albumin until the proximal anastomosis was performed.

\section{Aortocoronary Reversed SVG Bypass}

Under sterile conditions, a partial lower sternotomy was performed, and a chest retractor was placed. A Satinsky clamp was applied to partially occlude the ascending aorta, and an aortotomy was created. An end-to-side, running anastomosis was performed with 6-0 Prolene. An ACROBAT stabilizer (Guidant; Santa Clara, Calif) was positioned over the distal left anterior descending coronary artery. A coronary arteriotomy was created, and a standard end-to-side running anastomosis was performed with 7-0 Prolene. The proximal left anterior descending coronary artery was ligated, rendering the anterior left ventricle SVG-dependent. An ultrasonic vascular probe (Transonic Systems; Ithaca, NY) confirmed flow through the SVG. A mediastinal tube was inserted, the sternum was reapproximated with interrupted sutures, and the chest was closed in layers. Buprenorphine hydrochloride $(0.5 \mathrm{mg}$ intramuscularly) was administered every 8 to 12 hours for 48 hours after the surgery and then as needed. Dogs were maintained on buffered aspirin (325 mg/day) throughout the protocol.

\section{Arteriographic Confirmation of SVG Patency}

At postoperative days (PODs) 30,60, and 90, each dog underwent arteriography and intravascular ultrasound (IVUS) of SVGs. Dogs were sedated as before. Access to the femoral artery was obtained, and a vascular sheath was inserted. A $6 \mathrm{~F}$ coronary catheter was directed into the aortic root under fluoroscopic guidance. Radiodense contrast dye was used to find, gain access to, and confirm patency of the SVG.

\section{IVUS Monitoring of Graft Wall Thickness}

When possible, SVGs were imaged using a $6 \mathrm{~F}$ IVUS probe to monitor wall thickness. After access was gained to the distal SVG by the use of a guidewire, the IVUS probe was manually retracted to generate ultrasonic cross-sectional images of the SVG wall.

\section{Histologic Preparation}

After the POD 90 arteriogram, dogs were killed with a lethal dose of intra-arterial pentobarbital sodium $390 \mathrm{mg} / \mathrm{mL}$ and phenytoin sodium $50 \mathrm{mg} / \mathrm{mL}$ (Euthasol; Delmarva Laboratories, Midlothian, Va). Each SVG and nongrafted SV from the right hind limb were 


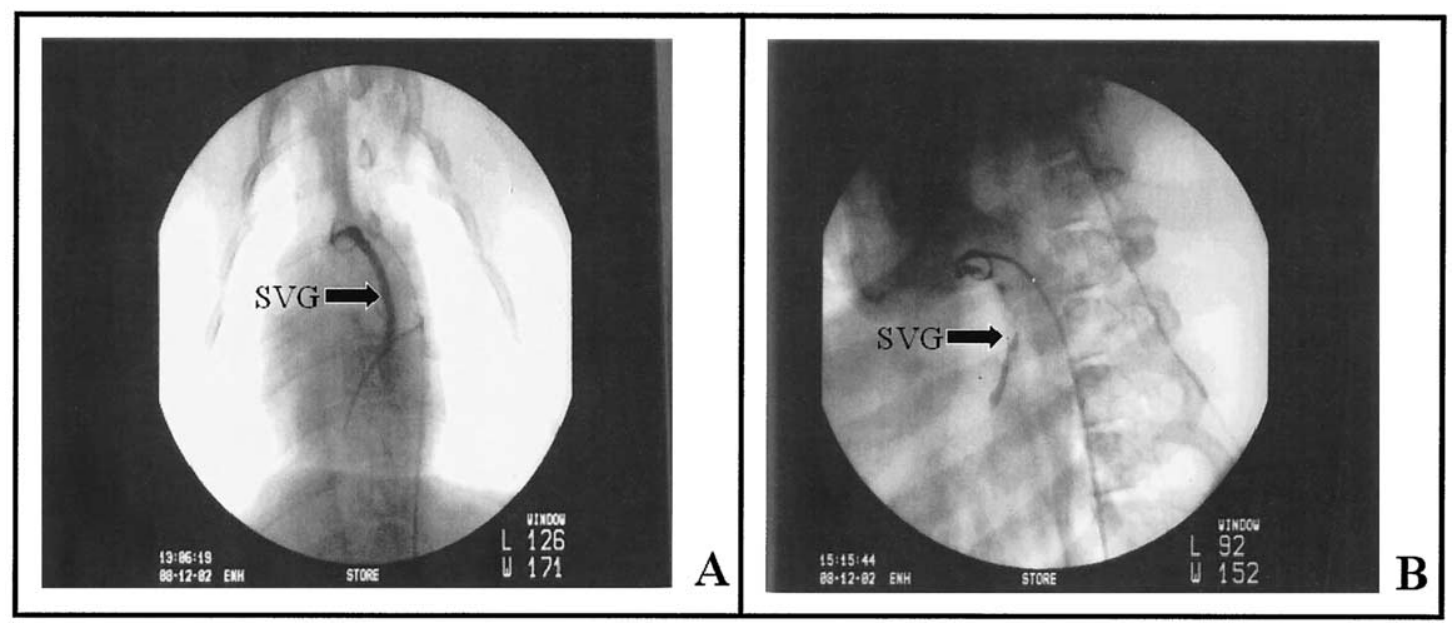

Figure 1. A, POD 30 arteriogram from a representative dog reveals a patent SVG devoid of filling defects. B, The same SVG is imaged on POD 90; multiple filling defects are apparent, suggestive of SVG disease and IH. SVG, Saphenous vein graft.

harvested and placed into $10 \%$ formalin for 24 hours. SVG and nongrafted SV segments were embedded in paraffin and cut in cross-section for histologic staining and measurements. Crosssections $(5 \mu \mathrm{m})$ were taken every $0.5 \mathrm{~cm}$ and prepared with a modified hematoxylin-eosin stain.

\section{Measurement of IH}

All SVG vessel sections were digitally photographed at $5 \times$ magnification. A photomicrograph demonstrating maximal $\mathrm{IH}$ from each third of each SVG was analyzed. For each SVG section analyzed, the intimal area, medial area, maximal wall thickness, and minimal wall thickness were determined using Image Tool v.3.0 (The University of Texas Health Sciences Center, San Antonio, Tex). Mean values were calculated for each SVG. The intima and media were delineated by the demarcation between the radial orientation of the intimal smooth muscle cells and the more circular orientation of the medial smooth muscle cells, as previously described. ${ }^{13}$ The outer limit of the media was defined by the interface between the circular smooth muscle cells of the media and the connective tissue of the adventitia. The ratio of the intimal and medial areas (intima area/media area) was calculated. Similar measurements and calculations were performed for 2 representative sections from each nongrafted SV.

\section{Confirmation of Transgene Expression in SVGs}

Dogs treated with adenoviruses $(n=4)$ were killed on POD 7 as before, and the SVG was harvested. For dogs treated with Adeno$\beta$-gal $(\mathrm{n}=2)$, specimens were mounted on a freezing microtome, and $10-\mu \mathrm{m}$ sections were transferred to pretreated glass slides. Sections were fixed in $10 \%$ formalin for 2 minutes at room temperature and washed in PBS; $\beta$-gal staining was performed as previously described. ${ }^{9}$ After staining $\left(30-60\right.$ minutes at $\left.37^{\circ} \mathrm{C}\right)$, the sections were rinsed in PBS solution and counterstained with eosin. For dogs treated with Adeno- $\beta$ ARKct $(n=2)$, the vessels were excised, total RNA was isolated, and Northern analysis was performed by standard methods previously described. ${ }^{9}$

\section{Statistical Analysis}

Comparisons between SVGs and nongrafted SVs were made using unpaired, 2-tailed Student $t$ tests. All data are represented as mean \pm SEM.

\section{Results}

\section{Assessment of SVG Patency}

SVGs from all dogs in this study $(\mathrm{n}=10)$ were confirmed patent immediately after completion of the distal anastomosis with an ultrasonic vascular flow probe. Flow values for each animal were $18 \mathrm{~mL} / \mathrm{min}$ or greater. Serial arteriograms at PODs 30, 60, and 90 revealed progressive filling defects consistent with graft wall thickening (Figure 1). At POD 30, most SVGs (4/6) were without filling defects. By POD 90, all SVGs displayed filling defects. Attempted serial IVUS confirmed the progression of SVG wall thickening, but this was obtained consistently only on POD 30 (5/6 dogs). By POD 90, the IVUS catheter could not be introduced into any of the diseased SVGs, and therefore IVUS was not performed.

\section{Histologic Analysis}

The mean intimal area of SVGs was increased compared with nongrafted SVs $\left(2.83 \pm 0.57 \mathrm{~mm}^{2}\right.$ vs $0.09 \pm 0.01$ $\left.\mathrm{mm}^{2}, P<.0008\right)$. Differences in mean medial area $(2.21 \pm$ $0.19 \mathrm{~mm}^{2}$ vs $\left.1.10 \pm 0.19 \mathrm{~mm}^{2}, P<.01\right)$, mean intima and media ratio $(1.22$ vs $0.09, P<.0001)$, mean maximal wall thickness $(1.94 \pm 0.18 \mathrm{~mm}$ vs $0.39 \pm 0.06 \mathrm{~mm}, P<.005)$, and mean minimal wall thickness $(0.71 \pm 0.08 \mathrm{~mm}$ vs 0.23 $\pm 0.03 \mathrm{~mm}, P<.0003)$ also were significant. Representative photomicrographs from a single dog are displayed in Figure 2. 


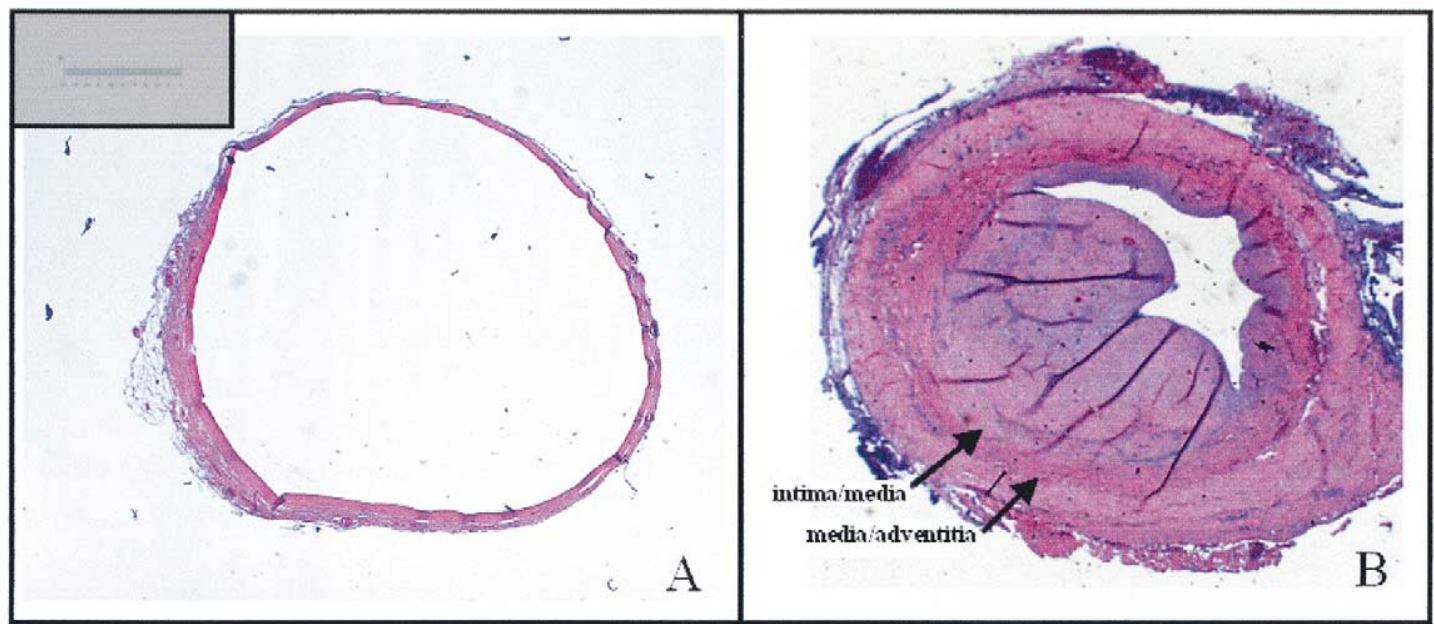

Figure 2. Hematoxylin-eosin-stained slides of (A) nongrafted SV and (B) SVG from a representative dog put to death on POD 90. Borders between the intima, media, and adventitia (arrows). Scale $=1 \mathrm{~mm}$.

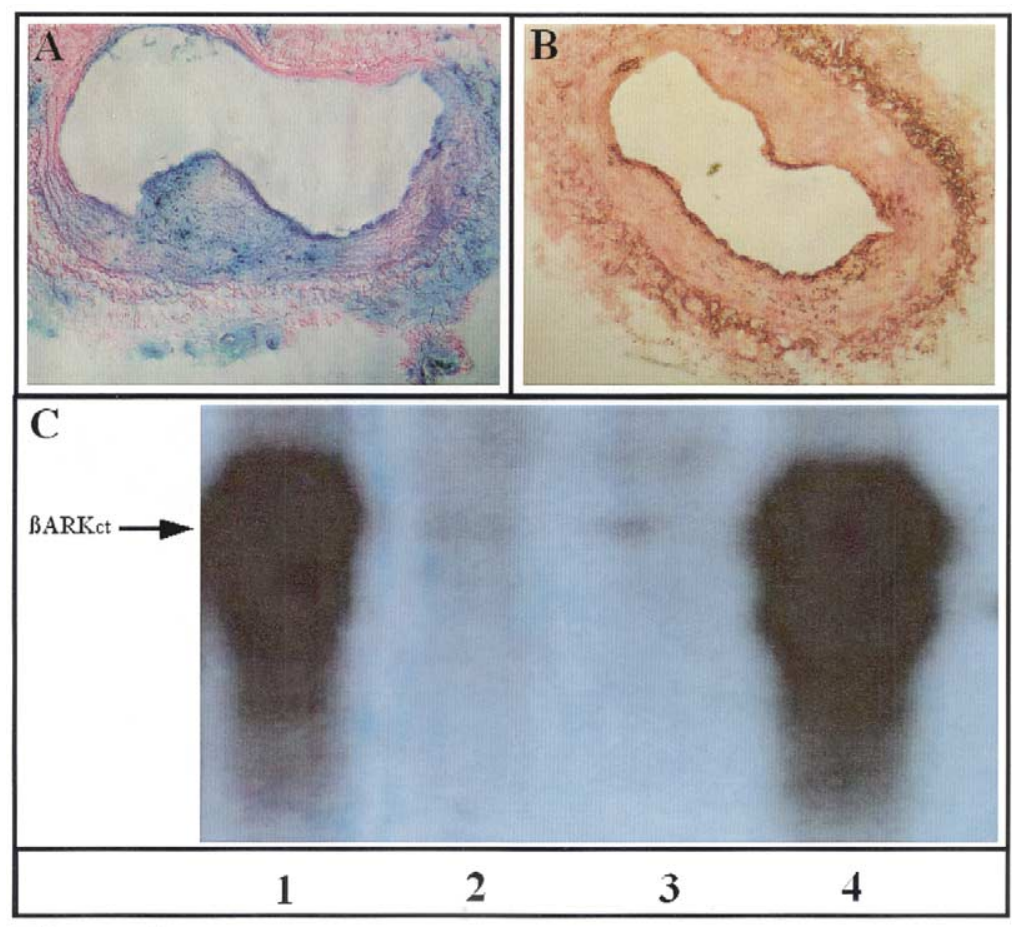

Figure 3. X-gal-stained sections of an Adeno- $\beta$-gal-treated SVG (A) versus nontreated SVG (B). Northern blot

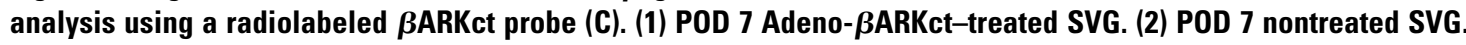
(3) Untreated myocardium (negative control). (4) Direct myocardial injection of Adeno- $\beta$ ARKct (positive control). $\beta A R K c t, \beta$-Adrenergic receptor kinase carboxyl terminus.

\section{Assessment of Gene Transfection}

A subset of $\operatorname{dogs}(n=4)$ had their SVGs treated with a replication-deficient, recombinant adenovirus. These animals were put to death on POD 7. Adeno- $\beta$-gal-treated SVGs $(\mathrm{n}=2)$ demonstrated nonuniform (patchy) transgene expres-sion by X-gal staining relative to untreated SVGs (Figure 3, $A$ and $B$ ). Gene expression was noted in all layers of the SVG wall. Adeno- $\beta$ ARKct-treated SVGs demonstrated transgene expression by Northern analysis relative to nontreated SVGs (Figure 3, C). 


\section{Discussion}

Aortocoronary SVG IH is a critical, initial event leading to subsequent vessel occlusion. Current treatment modalities are limited in their ability to effectively prevent this process. Novel genetic treatments directed at molecular targets to temper the development of vein graft IH are appealing and have generated considerable interest. However, a clinically relevant experimental model of aortocoronary SVG IH has not been fully characterized.

Previous studies have described the progression of SVG IH in canine aortocoronary SVGs. ${ }^{14-16}$ None of the previous investigations quantified the amount of $\mathrm{IH}$ that developed in the SVGs; each simply described the pathologic changes that occurred. In addition, the number of specimens analyzed at any single time point is very small. Silver and colleagues ${ }^{16}$ followed only 3 dogs (and only 1 at each of the 3 time points) to generate their conclusions. Brody and colleagues $^{15}$ included $29 \mathrm{dogs}$ in their study, but only 9 were killed for histologic analysis. Furthermore, only 2 of these 9 dogs were examined at POD 90. Finally, clinically relevant techniques were not used. For example, all of these articles describe distending the SV to $180 \mathrm{~mm} \mathrm{Hg}$ before implantation. The mechanical trauma and resultant decreased graft patency rates resulting from high-pressure distension are well described, and, accordingly, this practice is not clinically advisable. In contrast, the current article offers a clinically relevant model that is described by reproducible, statistically supported measurements.

For a model of vein graft IH to be pertinent, blood flow and graft patency must be maintained throughout the protocol. In this model, flow and patency were confirmed at regular intervals. Flow probe data confirmed SVG patency immediately after completion of the anastomoses. Serial arteriography on PODs 30, 60, and 90 confirmed SVG patency to the conclusion of the protocol. Arteriography and IVUS also provided qualitative data regarding disease formation in each SVG. These surveillance techniques avoided killing animals at earlier time points. Serial arteriograms noted the steady progression of diffuse SVG disease in each animal. By POD 90, filling defects were noted in all SVGs. IVUS confirmed that the filling defects noted on arteriogram were caused by overall wall thickening rather than mural thrombus.

Histologic analysis confirmed the earlier qualitative results by quantifying the extent of SVG disease. The mean intimal area was more than 30 times greater in the SVGs when compared with nongrafted SVs. The average medial thickening, intimal and medial ratio, maximal wall thickness, and minimal wall thickness were similarly increased in the SVGs.

The second objective of this study was to demonstrate that ex vivo transfer of a replication-deficient, recombinant adenovirus vector was possible in SVGs using a delivery technique that was unlikely to damage the vessel endothelium. Transgene delivery to SVGs is valuable because multiple molecular pathways have been identified as important contributors to IH formation and may represent targets for IH treatment. Inhibition of intracellular superoxides, extracellular matrix metalloproteinases, and nuclear apoptotic proteins impede VSMC proliferation and vascular $\mathrm{IH}^{8,17,18}$ Our laboratory demonstrated IH reduction in a rabbit peripheral vein graft model through inhibition of heterotrimeric G-protein-mediated mitogenic signaling. ${ }^{13,19}$ Specifically, we used a peptide inhibitor of G-protein beta-gamma subunits $\left(\mathrm{G}_{\beta \gamma}\right)$-the $\beta$ ARKct. $\beta$ ARKct is a peptide derived from the $\beta$ ARK that binds to $\mathrm{G}_{\beta \gamma}$ before that subunit's activation. ${ }^{20} \mathrm{G}_{\beta \gamma}$ seems to be a key molecule in VSMC proliferation. ${ }^{21}$

A previous study showed that ex vivo adenoviral-mediated transgene delivery was possible in canine aortocoronary SVGs. ${ }^{22}$ To achieve transgene expression, the investigators distended the $\mathrm{SV}$ at high pressures $(\approx 75 \mathrm{~mm} \mathrm{Hg})$ for 1 hour. Prior studies described an inverse relationship between preimplantation SVG manipulation and patency. ${ }^{4}$ Elevated distension pressures have been demonstrated to specifically injure the fragile SV endothelium that is a critical regulator for vessel hemostasis and VSMC proliferation. ${ }^{23-26}$ So, although this technique achieved transgene expression, prolonged high-pressure distension is not a common clinical practice. This delivery technique itself may disrupt the vessel endothelium and lead to IH.

We demonstrate a method of gene delivery using clinically relevant conditions. Both $\beta$-gal and $\beta$ ARKct were expressed in SVGs on POD 7 after distending the vessel lumen to subphysiologic pressures for 20 minutes. This finding is appealing because it offers a convenient, nontraumatic opportunity for focused SVG treatment. Ehsan and colleagues $^{27}$ used nondistending, high pressures $(300 \mathrm{~mm}$ $\mathrm{Hg}$ ) after placing the SV in an inelastic sheath to transfer DNA oligonucleotides. This technique focuses on delivering small DNA molecules rather than larger genes. Nonetheless, the principle of protecting the vessel endothelium by minimizing distension pressures remains important in any proposed treatment to limit SVG IH and enhance longterm patency. The gene transfer method described in this article warrants comparison with the high-pressure, nondistending technique.

This canine model of aortocoronary SVG IH is not without limitations. Although we attempted to maximize clinical relevance throughout this study, the time course to canine SVG IH is noticeably less than in humans. In patients, SVG IH typically takes years to become clinically significant, rather than weeks or months. One explanation of this abbreviated time course may be that the typical resting canine mean arterial blood pressure $(80-120 \mathrm{~mm} \mathrm{Hg}$ ) is higher compared with that of humans. ${ }^{28}$ This increased 
blood pressure may contribute to increased wall stress (and accelerated SVG IH) in the canine SV.

\section{Conclusion}

This study characterizes a large animal model of aortocoronary SVG IH that may serve as a testing ground for a variety of promising molecular therapies. In addition, it demonstrates that efficient transgene expression in the SVG vessel wall is possible following a clinically relevant, ex vivo treatment with replication-deficient, recombinant adenovirus vectors.

We thank the Genzyme Corporation for production of Adeno$\beta$ ARKct. We also thank George Quick, Ronald Johnson, Elaine Parker, and Mike Lowe for their valuable technical support during all procedures in this study.

\section{References}

1. Campeau L, Enjalbert M, Lesperance J, Vaislic C, Grondin CM, Bourassa MG. Atherosclerosis and late closure of aortocoronary saphenous vein grafts: sequential angiographic studies at 2 weeks, 1 year, 5 to 7 years, and 10 to 12 years after surgery. Circulation. 1983;68(3 Pt 2):II1-7.

2. Bourassa MG, Campeau L, Lesperance J, Grondin CM. Changes in grafts and coronary arteries after saphenous vein aortocoronary bypass surgery: results at repeat angiography. Circulation. 1982;65(7 Pt 2): 90-7

3. Newby AC, Zaltsman AB. Molecular mechanisms in intimal hyperplasia. J Pathol. 2000;190:300-9.

4. Souza DS, Dashwood MR, Tsui JC, Filbey D, Bodin L, Johansson B, et al. Improved patency in vein grafts harvested with surrounding tissue: results of a randomized study using three harvesting techniques. Ann Thorac Surg. 2002;73:1189-95.

5. Goldman S, Copeland J, Moritz T, Henderson W, Zadina K, Ovitt T, et al. Improvement in early saphenous vein graft patency after coronary artery bypass surgery with antiplatelet therapy: results of a Veterans Administration Cooperative Study. Circulation. 1988;77: 1324-32.

6. Stein PD, Dalen JE, Goldman S, Schwartz L, Turpie AG, Theroux P. Antithrombotic therapy in patients with saphenous vein and internal mammary artery bypass grafts following percutaneous transluminal coronary angioplasty. Chest. 1992;102(4 Suppl):508S-15S.

7. Yoshimura S, Morishita R, Hayashi K, Yamamoto K, Nakagami H, Kaneda Y, et al. Inhibition of intimal hyperplasia after balloon injury in rat carotid artery model using cis-element "decoy" of nuclear factor-kappaB binding site as a novel molecular strategy. Gene Ther. 2001;8:1635-42.

8. Laukkanen MO, Kivela A, Rissanen T, Rutanen J, Karkkainen MK, Leppanen O, et al. Adenovirus-mediated extracellular superoxide dismutase gene therapy reduces neointima formation in balloon-denuded rabbit aorta. Circulation. 2002;106:1999-2003.

9. Iaccarino G, Smithwick LA, Lefkowitz RJ, Koch WJ. Targeting Gbeta gamma signaling in arterial vascular smooth muscle proliferation: a novel strategy to limit restenosis. Proc Natl Acad Sci U S A. 1999;96: 3945-50.

10. Mangi AA, Dzau VJ. Gene therapy for human bypass grafts. Ann Med. 2001;33:153-5.

11. Morishita R, Gibbons GH, Horiuchi M, Ellison KE, Nakama M, Zhang L, et al. A gene therapy strategy using a transcription factor decoy of the E2F binding site inhibits smooth muscle proliferation in vivo. Proc Natl Acad Sci U S A. 1995;92:5855-9.

12. White DC, Hata JA, Shah AS, Glower DD, Lefkowitz RJ, Koch WJ. Preservation of myocardial beta-adrenergic receptor signaling delays the development of heart failure after myocardial infarction. Proc Natl Acad Sci U S A. 2000;97:5428-33.
13. Davies MG, Huynh TT, Fulton GJ, Lefkowitz RJ, Svendsen E, Hagen PO, et al. G protein signaling and vein graft intimal hyperplasia: reduction of intimal hyperplasia in vein grafts by a Gbetagamma inhibitor suggests a major role of $\mathrm{G}$ protein signaling in lesion development. Arterioscler Thromb Vasc Biol. 1998;18:1275-80.

14. Silver MD, MacGregor DC, Agarwal VK, Lixfeld W. Aortocoronary bypass graft: early histologic changes in dogs. Can J Surg. 1973;16: 246-51.

15. Brody WR, Angell WW, Kosek JC. Histologic fate of the venous coronary artery bypass in dogs. Am J Pathol. 1972;66:111-9.

16. Silver MD, Wilson GJ, Lixfeld W, Trimble AS, MacGregor DC. Aortocoronary bypass graft in dogs: late histologic changes. Pathology. 1976;8:343-51.

17. Tsukioka K, Suzuki J, Fujimori M, Wada Y, Yamaura K, Ito K, et al. Expression of matrix metalloproteinases in cardiac allograft vasculopathy and its attenuation by anti MMP-2 ribozyme gene transfection. Cardiovasc Res. 2002;56:472-8.

18. Huang J, Kontos CD. PTEN modulates vascular endothelial growth factor-mediated signaling and angiogenic effects. J Biol Chem. 2002; 277:10760-6.

19. Koch WJ, Inglese J, Stone WC, Lefkowitz RJ. The binding site for the beta gamma subunits of heterotrimeric $\mathrm{G}$ proteins on the beta-adrenergic receptor kinase. J Biol Chem. 1993;268:8256-60.

20. Koch WJ, Hawes BE, Inglese J, Luttrell LM, Lefkowitz RJ. Cellular expression of the carboxyl terminus of a $\mathrm{G}$ protein-coupled receptor kinase attenuates $\mathrm{G}$ beta gamma-mediated signaling. J Biol Chem. 1994;269:6193-7.

21. Iaccarino G, Koch WJ. G beta gamma-mediated signaling: new therapeutic target for proliferative vascular disease. IUBMB Life. 1999;48: 257-61.

22. Chiu-Pinheiro CK, O’Brien T, Katusic ZS, Bonilla LF, Hamner CE, Schaff HV. Gene transfer to coronary artery bypass conduits. Ann Thorac Surg. 2002;74:1161-6.

23. Chester AH, Buttery LD, Borland JA, Springall DR, Rothery S, Severs NJ, et al. Structural, biochemical and functional effects of distending pressure in the human saphenous vein: implications for bypass grafting. Coron Artery Dis. 1998;9:143-51.

24. Hausmann H, Merker HJ, Hetzer R. Pressure controlled preparation of the saphenous vein with papaverine for aortocoronary venous bypass. J Card Surg. 1996;11:155-62.

25. Kennedy JH, Lever MJ, Addis BJ, Paneth M. Changes in vein interstitium following distension for aortocoronary bypass. J Card Surg. 1989;30:992-5.

26. Angelini GD, Passani SL, Breckenridge IM, Newby AC. Nature and pressure dependence of damage induced by distension of human saphenous vein coronary artery bypass grafts. Cardiovasc Res. 1987; 21:902-7.

27. Ehsan A, Mann MJ, Dell' Acqua G, Dzau VJ. Long-term stabilization of vein graft wall architecture and prolonged resistance to experimental atherosclerosis after E2F decoy oligonucleotide gene therapy. J Thorac Cardiovasc Surg. 2001;121:714-22.

28. Muir WW, Hubbell JAE, Skarda RT, Bednarski RM. The handbook of veterinary anesthesia. 3rd ed. New York: Mosby; 2000.

\section{Discussion}

Dr Frank W. Sellke (Boston, Mass). That was a very nice presentation. Vein graft disease after aortocoronary surgery is a long-term issue or problem. Do you think that you could transfect the veins with a gene that may have more of a long-term consequences as opposed to $\beta$ ARK (which may have short-term effects)? If so, what would those genes be?

Dr Petrofski. Well, more so than just a specific gene would be the virus on which the transgene is carried. We are using a first-generation viral vector, which in our laboratory produces transgene expression for approximately 14 days. Other virus carriers may produce longer transgene expression. Certainly retroviruses incorporate into the host genome and theoretically result in indefinite transgene expression. This of course leads you to the 
potential problem that transgene expression would remain forever, and any long-term effects could become deleterious.

Dr Sellke. I was curious that you used $\beta A R K$, which is a protein involved with signal transduction in the adrenergic pathway. How does this inhibit IH?

Dr Petrofski. That is a good question. What we are using is actually the carboxyl terminus of $\beta$ ARK, which is the last 194 amino acids. The proposed mechanism that we have seen in previous in vitro work in isolated VSMCs and in some rabbit models of jugular vein interposition grafts is that the $\beta \mathrm{ARKct}$ blocks the beta gamma subunit of G-protein-coupled receptors. In work by Drs Koch and Lefkowitz, G-protein-coupled receptors have been shown to stimulate the Ras/mitogen-activated protein (MAP) kinase pathway. That Ras/MAP kinase pathway is critical in VSMC proliferation. So the last 194 amino acids, the carboxyl terminus, competitively inhibits that beta gamma subunit, and that is the proposed mechanism that we are working with at this point.

Dr Sellke. How about giving a MAP kinase inhibitor or some gene encoding a protein that would effectively do that? Is that another potential treatment?

Dr Petrofski. This area of IH in diseased coronary arteries and vein grafts is under active investigation by laboratories throughout the country, and although I am not familiar with every gene out there, clearly there are multiple genes just at our institution that we are going to try in this model. In fact, the way that the $\beta$ ARKct works is by inhibiting the stimulus of the MAP kinase pathway.

Dr Aftab R. Kherani (New York, NY). I enjoyed your talk, and in line with your first future consideration, do you have any early long-term data comparable to that obtained while developing your model at PODs 30, 60, or 90 in regard to $\beta$ ARKct?

Dr Petrofski. Obviously the point of doing all this is not just an academic exercise but to actually test genes in this model, and we started by treating the grafts with Adeno- $\beta$ ARKct. Our initial data are quite encouraging with 6 dogs in each branch of the testing ( 6 controls and $6 \beta$ ARKct-treated dogs). The intimal area was decreased approximately $50 \%$ in the $\beta$ ARKct-treated grafts, which is consistent with previous studies from our laboratory in the rabbit model and also in VSMC proliferation in isolated in vitro studies.

Dr Paul A. Kurlansky (Miami Beach, Fla). I enjoyed your presentation. Just a quick thought regarding an issue that Dr Sellke raised. The stimulus for hyperplasia, although it may occur early, may persist throughout the life of the graft. However, to the extent that the cells are viable, the vector, once introduced, does not have to remain. The gene, once implanted, may become active, and there are various genes that can be turned on and off with various signals. That is perhaps a rich area to explore in this particular model so that you can get a long-term effect that could be modulated with drug therapy over time.

Dr Petrofski. I appreciate the comments. IH is a very complex pathology that has multiple stimuli, and we are only beginning to understand all of them. We hope, though, that with continued investigation and potentially newer viral backbones that we can keep the gene in longer, which may be a long-term benefit in this disease. 